\title{
Takotsubo Cardiomyopathy-Induced Cardiac Free Wall Rupture: A Case Report and Review of Literature
}

\author{
Mina Iskander ${ }^{\mathrm{a}, \mathrm{e}}$, Ashraf Abugroun ${ }^{\mathrm{b}}$, Kerolus Shehata ${ }^{\mathrm{c}}$, \\ Fady Iskander ${ }^{\mathrm{a}}$, Ayman Iskander ${ }^{\mathrm{d}}$
}

\begin{abstract}
Takotsubo cardiomyopathy (TCM) is an acquired form of cardiomyopathy that is commonly seen among post-menopausal women. It is characterized by left ventricular apical ballooning, electrocardiographic changes and mild elevation of cardiac enzymes in the absence of significant coronary artery stenosis. TCM usually has benign course. However, on rare instance, it can result in life-threatening and fatal complications including acute cardiogenic shock, ventricular arrhythmias and ventricular wall rupture. We herein report a case of a 77-year-old female who developed TCM complicated with massive pericardial effusion and cardiac arrest. The patient died and autopsy revealed normal coronaries with a slit-like rupture on the anteroapical surface of the heart extending into the papillary muscle. The clinical course, labs and angiographic findings preceding the cardiac rupture will be outlined. A thorough literature review including review of 14 previously reported case reports of TCM complicated with cardiac rupture will be included.
\end{abstract}

Keywords: Takotsubo; Cardiomyopathy; Ventricular wall rupture

\section{Introduction}

Takotsubo Cardiomyopathy (TCM) is an acquired reversible cardiomyopathy that occurs mostly in postmenopausal females. The condition is relatively rare, account for $1-2 \%$ of all suspected acute coronary syndromes [1]. Majority of patients are either Asians or Caucasians. In previously reported cases, $57.2 \%$ of patients were Asian, $40 \%$ were Caucasian and $2.4 \%$ were other races [2]. The pathogenesis of the condition

Manuscript submitted April 26, 2018, accepted May 7, 2018

aJohn H. Stroger, Jr. Hospital of Cook County, Chicago, IL 60612, USA

${ }^{\mathrm{b} A d v o c a t e}$ Illinois Masonic Medical Center, Chicago, IL 60657, USA

'St. Joseph's Hospital Health Center, Heart Journal 301 Prospect Ave, Syracuse, NY 13203, USA

dSJH Cardiology Associates, 4820 West Taft Road, Suite 209, Liverpool, NY 13088, USA

${ }^{e}$ Corresponding Author: Mina Iskander, John H. Stroger, Jr. Hospital of Cook County, 3139 N Campbell Ave, Chicago, IL 60618, USA.

Email: miskander@cookcountyhhs.org

doi: https://doi.org/10.14740/cr728w is still unclear, but catecholamine-induced cardiotoxicity has been described as a main potential contributor. TCM simulates acute coronary syndrome (ACS) in its presentation, as it is characterized by acute chest pain with EKG ischemic changes and slight elevation on cardiac enzymes. However, unlike ACS, the condition is characterized by presence of normal coronary arteries on catheterization. TCM has favorable prognosis. Heart failure with or without pulmonary edema is the most commonly seen complications. Rarely, serious complications could arise including development of ventricular arrhythmia, thromboembolic phenomena and ventricular free wall rupture.

\section{Case Report}

A 77-year-old female with a history of hypertension was brought to the emergency department (ED) $2 \mathrm{~h}$ after she was found unconscious at her apartment. Upon arrival to the ED, she regained her consciousness, but sustained a pressure-like chest pain with mild shortness of breath. She was hemodynamically stable with a blood pressure of $100 / 72 \mathrm{~mm} \mathrm{Hg}$ and regular pulse rate of 72 beats/min. Physical examination was within normal limits. Her initial EKG showed a $2 \mathrm{~mm}$ ST-segment elevation in leads I, aVL and V2 - V6. Troponin T level was $3.6 \mathrm{ng} / \mathrm{mL}$ (reference range is $<0.01 \mathrm{ng} / \mathrm{mL}$ ). Emergent transthoracic echocardiogram (TTE) showed severe dyskinesia of the anterolateral walls of the left ventricle (LV) with no left ventricular outflow tract (LVOT) obstruction or systolic anterior motion (SAM) of the mitral valve. She was given aspirin, IV heparin, nitroglycerine, thrombolytic therapy, and then was referred to our hospital for escalation of care. Subsequently, a coronary angiography was done and revealed normal coronary arteries with no obstructions, but with a slow flow down the left anterior descending artery (LAD). Left ventriculography (Fig. 1) showed apical ballooning with mild to moderate mitral regurgitation consistent with TCM, she had an ejection fraction of $25 \%$ and left ventricular end diastolic pressure (LVEDP) of $35 \mathrm{~mm} \mathrm{Hg}$. Shortly after the procedure, the patient suddenly developed a severe sharp chest pain with a rapid drop in her blood pressure. Bedside echocardiogram showed a massive pericardial effusion for which emergent pericardiocentesis was performed. The patient's condition rapidly deteriorated and developed a cardiac arrest. The patient didn't respond to the extensive trials of resuscitation and she ultimately expired. 

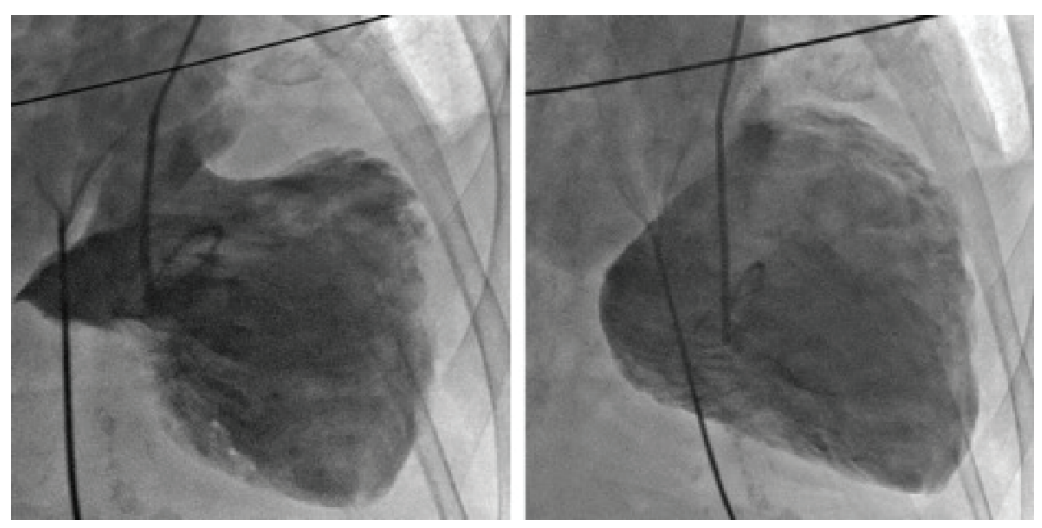

Figure 1. Left ventriculogram showing the characteristic apical ballooning of TCM with moderate to severe mitral regurgitation.

Gross pathology revealed normal coronary arteries without any atherosclerotic stenosis (Fig. 2). The heart weighs $380 \mathrm{~g}$ with a large fresh blood clot on its epicardial surface. There was a $3 \times 2 \mathrm{~cm}$ area of transmural hemorrhage with a slit-like rupture on the antero-apical surface that extends into the papillary muscles (Fig. 3). Free wall thickness of the right ventricle (RV) was $0.5 \mathrm{~cm}$. and that of LV was $2 \mathrm{~cm}$. Microscopically, there were extensive fresh hemorrhagic foci and neutrophilic infiltration between the cardiac myocytes associated with hyper eosinophilic contraction band necrosis (CBN) (Fig. 4).

\section{Discussion}

Takotsubo cardiomyopathy (TCM) was first described in a series of Japanese patients by Dote and Sato in 1991 [3]. TCM accounts for $1-2 \%$ of cases that present with ACS [1], but it may be underdiagnosed due to a lack of clinical suspicion. The condition is much more common in women, particularly after menopause. Both males and females have similar clinical presentation, trigger factors and prognosis [4].

TCM typically present with chest pain and shortness of press resembling acute MI. It can also present with arrhyth-

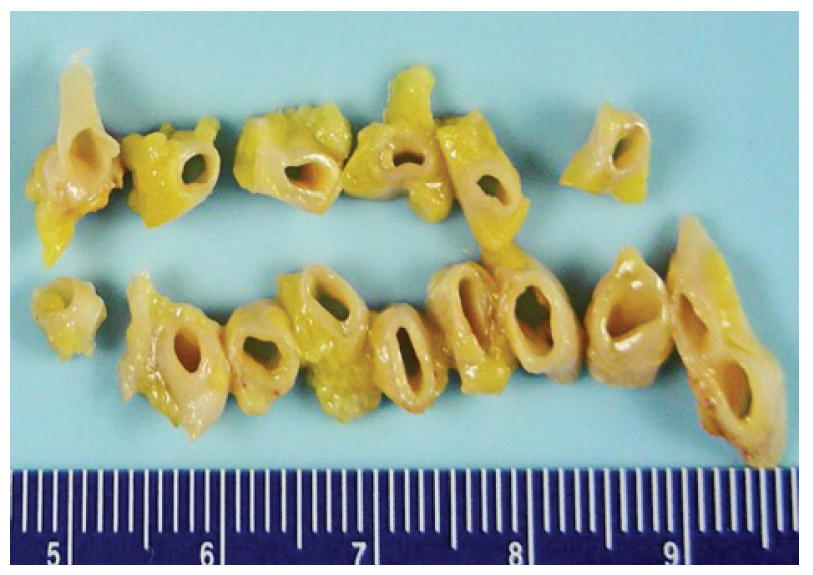

Figure 2. Normal sections of the left anterior descending coronary artery without atherosclerotic stenosis or plaque rupture. mias, pre-syncope or syncope, pulmonary edema or even sudden death. TCM carries a good prognosis and up to $96 \%$ of patients end with complete recovery from their symptoms [5]. Common triggers for the condition include exposure to emotional or physical stressor and in some cases no trigger or precipitant stressor can be identified. EKG changes in TCM include ST segment elevation along precordial leads, T-wave inversion and development of Q-waves. Characteristic angiographic findings of TCM include (LV) apical ballooning lack of significant coronary stenosis $[1,6]$. Other variant forms of TCM include isolated basal, mid-ventricular, or apical segment involvement [7]. The revised Mayo Criteria are currently the most commonly used to establish a diagnosis of TCM were a combination of clinical presentation, EKG, TTE and angiographic findings are collectively incorporated in making the diagnosis [8].

Although the exact pathophysiologic mechanisms of TCM is still not well-established, the role of catecholamine seems to be central through the brain-heart axis [9]. Further supporting the role of sympathetic stimulation, Abraham et al described a series of nine patients who developed features of acute stress cardiomyopathy following administration of exogenous sympathomimetic agents [10]. In addition, on a large multi-center study based on the International Takotsubo Registry, patients with TCM had higher prevalence of neurologic and psychiatric problems compared with patients diagnosed with ACS [11]. Although many reports have suggested that the prognosis of TCM is generally favorable with restoration of wall motion in few weeks with conservative therapy, there have been reports of potentially fatal outcomes.

According to TCM registry study, the over-all TCM related mortality was $4.1 \%$ and cardiogenic shock developed in $9.9 \%$ of patients [11]. Other potential complications of TCM include LV thrombosis [12], development of ventricular septal defect (VSD) [13, 14], mitral regurgitation [15], life-threatening arrhythmias [16] and ventricular free wall rupture (FWR) [17]. Of all the aforementioned complications of TCM, cardiac FWR is the most catastrophic. FWR is extremely rare complication with incidence rate of $0.5 \%$ [17]. A review of previously reported cases of TCM complicated with FWR is summarized in Table 1 [18-32].

Risk factors for FWR are similar in both TCM and acute 


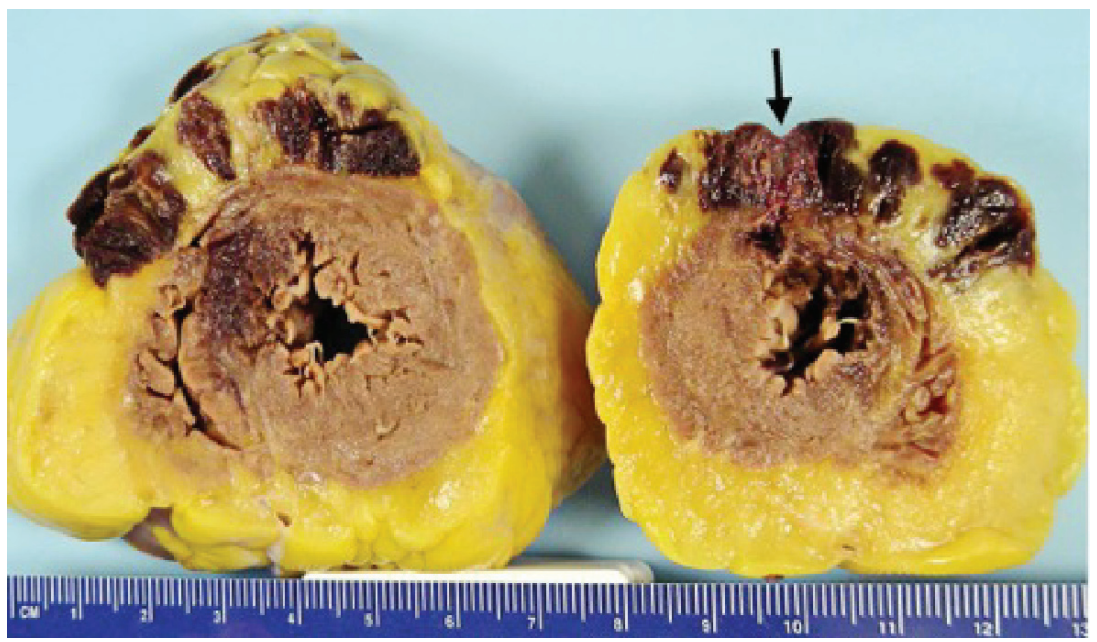

Figure 3. Mid-ventricular and apical cut sections of the heart showing an area of transmural hemorrhage with an apical slit-like rupture (black arrow).

MI and include female gender, advanced age and presence of hypertension [18]. ST elevation in TCM is usually transient and generally recovers within several days after the onset of symptoms [6]. Persistent STE is a warning sign for continued myocardial injury and heralds an impending ventricular FWR $[19,20]$. Other predictors for FWR include higher levels of troponin and CPK, elevated LV intramural pressure and wall stress evident with elevated left ventricular outflow tract (LVOT) gradient [21, 22].

FWR is commonly reported among patients with apical form of TCM which may suggest a much more benign course of the mid-ventricular and basal forms of the TCM. Histologically, recognized patterns of myocardial cell death include coagulation necrosis which is also seen in other solid organ infarction, colliquative necrosis that occurs in the low output states and the coagulative myocytolysis with contraction band necrosis $(\mathrm{CBN})$ which is commonly seen on catecholamine myotoxicity [33]. Among patients with TCM complicated with FWR, recognized histopathological patterns of myocardial tissue biopsy include presence of intensely eosinophilic CBN as well as lymphocytic infiltration and localized areas of fibrosis $[21,24,25]$. These findings demonstrate a major role of catecholamines in the pathogenesis of TCM-induced cardiac
FWR.

Currently, there is no standard management protocol for patients with TCM. Although $\beta$-blockers have been broadly suggested for preventing the progression and recurrence of TCM [34], results from The International Takotsubo Registry suggested that there was no evidence of any survival benefit with the use of $\beta$-blockers . The same study demonstrated that the use of angiotensin-converting-enzyme inhibitors (ACE-I) or angiotensin-receptor blockers (ARBs) was associated with improved survival at 1 year. Further studies are needed to clarify the role of $\beta$-blockers, ACE-I or ARBs in the prevention of TCM-induced cardiac FWR.

\section{Conclusions}

TCM is not a benign disorder. It is associated with a substantial risk for adverse events e.g. arrhythmias, cardiogenic shock, pulmonary edema, systemic thromboembolism, cardiac rupture or even sudden death. Cardiac FWR is an extremely rare but potentially catastrophic complication of TCM. Initial EKG findings of persistently elevated ST-segment in patients with TCM may be useful to predict a more serious course of disease
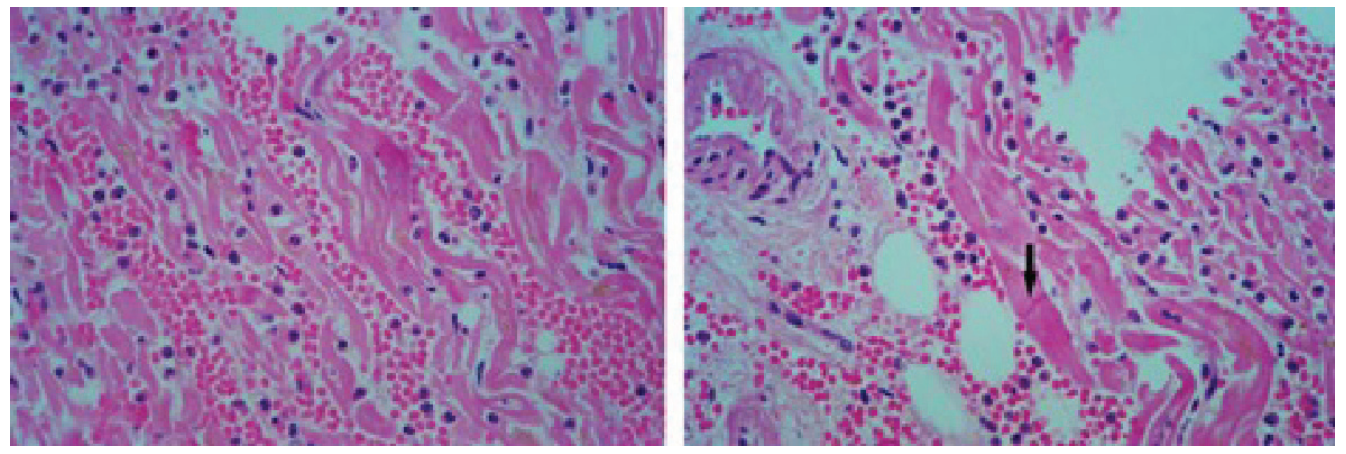

Figure 4. Histopathology slides at the rupture site showing areas of hemorrhagic foci with polymorphnuclear cells infiltrates between the cardiac myocytes and hypereosinophilic contraction band necrosis (black arrow). 


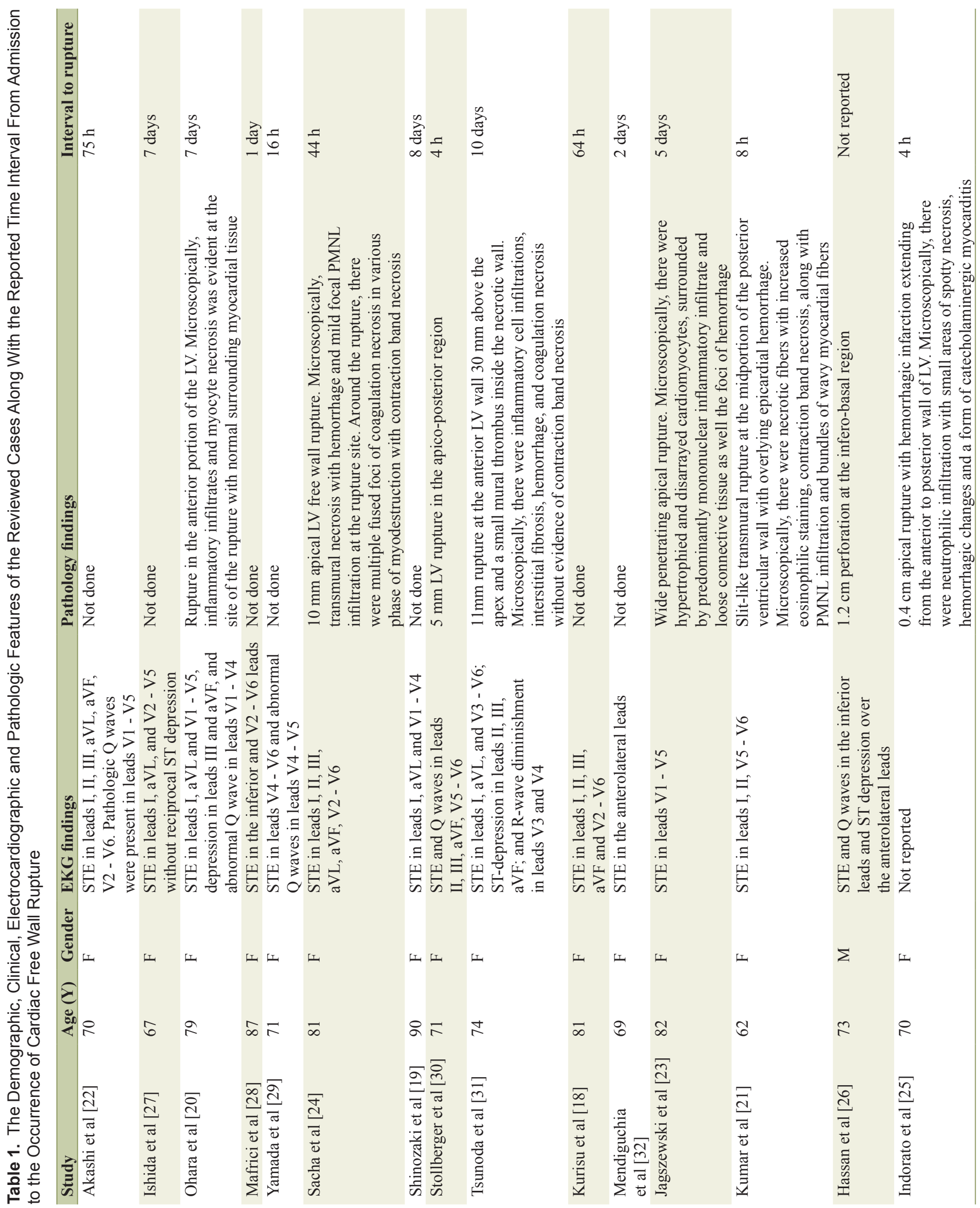


progression and provide a valuable parameter for risk stratification. The pathologic findings at the site of cardiac rupture suggest an important role of catecholamine-induced cardiotoxicity. Further studies are needed to provide an evidence-based guidance on appropriate medical therapy and to investigate the roles of $\beta$-blockers and ACE-I in the prevention of TCMinduced cardiac rupture.

\section{Acknowledgments}

We thank Dr. James Flynn for his help in the interpretation of the histopathology slides.

\section{Abbreviations}

TCM: takotsubo cardiomyopathy; FWR: free wall rupture; RBBB: right bundle branch block; ACS: acute coronary syndrome; LV: left ventricle; RV: right ventricle; STE: ST-segment elevation; $\mathrm{CBN}$ : contraction band necrosis; $\mathrm{CPK}$ : creatinine phosphokinase; ACE-I: angiotensin converting enzyme inhibitors; ARBs: angiotensin receptor blockers; M: male; F: female; LVEDP: left ventricular end diastolic pressure; LVOT: left ventricular outflow tract; SAM: systolic anterior motion; VSD: ventricular septal defect; EKG: electrocardiogram; MI: myocardial infarction

\section{References}

1. Akashi YJ, Goldstein DS, Barbaro G, Ueyama T. Takotsubo cardiomyopathy: a new form of acute, reversible heart failure. Circulation. 2008;118(25):2754-2762.

2. Donohue D, Movahed MR. Clinical characteristics, demographics and prognosis of transient left ventricular apical ballooning syndrome. Heart Fail Rev. 2005;10(4):311316.

3. Dote K, Sato H, Tateishi H, Uchida T, Ishihara M. [Myocardial stunning due to simultaneous multivessel coronary spasms: a review of 5 cases]. J Cardiol. 1991;21(2):203214.

4. Wittstein IS, Thiemann DR, Lima JA, Baughman KL, Schulman SP, Gerstenblith G, Wu KC, et al. Neurohumoral features of myocardial stunning due to sudden emotional stress. N Engl J Med. 2005;352(6):539-548.

5. Elesber AA, Prasad A, Lennon RJ, Wright RS, Lerman A, Rihal CS. Four-year recurrence rate and prognosis of the apical ballooning syndrome. J Am Coll Cardiol. 2007;50(5):448-452.

6. Abe Y, Kondo M, Matsuoka R, Araki M, Dohyama K, Tanio H. Assessment of clinical features in transient left ventricular apical ballooning. J Am Coll Cardiol. 2003;41(5):737-742.

7. Hurst RT, Prasad A, Askew JW, 3rd, Sengupta PP, Tajik AJ. Takotsubo cardiomyopathy: a unique cardiomyopathy with variable ventricular morphology. JACC Cardiovasc Imaging. 2010;3(6):641-649.
8. Scantlebury DC, Prasad A. Diagnosis of Takotsubo cardiomyopathy. Circ J. 2014;78(9):2129-2139.

9. Samuels MA. The brain-heart connection. Circulation. 2007;116(1):77-84.

10. Abraham J, Mudd JO, Kapur NK, Klein K, Champion HC, Wittstein IS. Stress cardiomyopathy after intravenous administration of catecholamines and beta-receptor agonists. J Am Coll Cardiol. 2009;53(15):1320-1325.

11. Templin C, Ghadri JR, Diekmann J, Napp LC, Bataiosu DR, Jaguszewski M, Cammann VL, et al. Clinical Features and Outcomes of Takotsubo (Stress) Cardiomyopathy. N Engl J Med. 2015;373(10):929-938.

12. de Gregorio C, Grimaldi P, Lentini C. Left ventricular thrombus formation and cardioembolic complications in patients with Takotsubo-like syndrome: a systematic review. Int J Cardiol. 2008;131(1):18-24.

13. Izumi K, Tada S, Yamada T. A case of Takotsubo cardiomyopathy complicated by ventricular septal perforation. Circ J. 2008;72(9):1540-1543.

14. Sakai K, Ochiai H, Katayama N, Nakamura K, Arataki K, Kido T, Iwamoto H, et al. Ventricular septal perforation in a patient with takotsubo cardiomyopathy. Circ J. 2005;69(3):365-367.

15. Haghi D, Rohm S, Suselbeck T, Borggrefe M, Papavassiliu T. Incidence and clinical significance of mitral regurgitation in Takotsubo cardiomyopathy. Clin Res Cardiol. 2010;99(2):93-98.

16. Stiermaier T, Eitel C, Denef S, Desch S, Schuler G, Thiele H, Eitel I. Prevalence and Clinical Significance of LifeThreatening Arrhythmias in Takotsubo Cardiomyopathy. J Am Coll Cardiol. 2015;65(19):2148-2150.

17. Bybee KA, Kara T, Prasad A, Lerman A, Barsness GW, Wright RS, Rihal CS. Systematic review: transient left ventricular apical ballooning: a syndrome that mimics ST-segment elevation myocardial infarction. Ann Intern Med. 2004;141(11):858-865.

18. Kurisu S, Inoue I. Cardiac rupture in tako-tsubo cardiomyopathy with persistent ST-segment elevation. Int J Cardiol. 2012;158(1):e5-6.

19. Shinozaki K, Tamura A, Abe Y, Yano S, Kadota J. Left ventricular free wall rupture in takotsubo cardiomyopathy. Int J Cardiol. 2007;115(1):e3-4.

20. Ohara Y, Hiasa Y, Hosokawa S, Tomokane T, Yamaguchi K, Ogura R, Miyajima H, et al. Left ventricular free wall rupture in transient left ventricular apical ballooning. Circ J. 2005;69(5):621-623.

21. Kumar S, Kaushik S, Nautiyal A, Choudhary SK, Kayastha BL, Mostow N, Lazar JM. Cardiac rupture in takotsubo cardiomyopathy: a systematic review. Clin Cardiol. 2011;34(11):672-676.

22. Akashi YJ, Tejima T, Sakurada H, Matsuda H, Suzuki K, Kawasaki K, Tsuchiya K, et al. Left ventricular rupture associated with Takotsubo cardiomyopathy. Mayo Clin Proc. 2004;79(6):821-824.

23. Jaguszewski M, Fijalkowski M, Nowak R, Czapiewski P, Ghadri JR, Templin C, Rynkiewicz A. Ventricular rupture in Takotsubo cardiomyopathy. Eur Heart J. 2012;33(8):1027.

24. Sacha J, Maselko J, Wester A, Szudrowicz Z, Pluta W. 
Left ventricular apical rupture caused by takotsubo cardiomyopathy - comprehensive pathological heart investigation. Circ J. 2007;71(6):982-985.

25. Indorato F, Akashi YJ, Rossitto C, Raffino C, Bartoloni G. Takotsubo cardiomyopathy associated with rupture of the left ventricular apex: assessment of histopathological features of a fatal case and literature review. Forensic Sci Med Pathol. 2015;11(4):577-583.

26. S YH. Cardiac rupture in a patient with Takotsubo syndrome triggered by acute myocardial infarction: two messages. Int J Cardiol. 2014;177(1):162-165.

27. Ishida T, Yasu T, Arao K, Kawakami M, Saito M. Images in cardiovascular medicine. Bedside diagnosis of cardiac rupture by contrast echocardiography. Circulation. 2005;112(24):e354-355.

28. Mafrici A, Proietti R, Fusco R, De Biase A, Klugmann S. Left ventricular free wall rupture in a Caucasian female with Takotsubo syndrome: a case report and a brief literature review. J Cardiovasc Med (Hagerstown). 2006;7(12):880-883.

29. Ryotaro Yamada NW, Teruyoshi Kume, Takahiro Kawamoto, Noriko Okahashi, Nozomi Wada, Yuji Koy- ama, Eiji Toyota, et al. Left ventricular rupture associated with takotsubo-like left ventricular dysfunction (Apical Ballooning). J Echocardiogr. 2006;4(2):59-62.

30. Stollberger C, Huber JO, Enzelsberger B, Finsterer J. Fatal outcome of epileptic seizure-induced takotsubo syndrome with left ventricular rupture. Eur J Neurol. 2009;16(6):e116-117.

31. Tsunoda S, Tando S, Doi T, Kitamura Y, Ogawa M, Tanabe $S$, et al. Left ventricular free wall rupture associated with a combination of acute myocardial infarction and stress-provoked cardiomyopathy: An autopsy case. J Cardiol Cases. 2010;2(3):e119-e122.

32. Salazar-Mendiguchia J, Ariza A, Sanchez JC, Lorente $\mathrm{V}$, Cequier AR. An unusual complication of a Takotsubo cardiomyopathy: a not so benign disease? Int J Cardiol. 2011;150(3):348-349.

33. Baroldi G. Different morphological types of myocardial cell death in man. Recent Adv Stud Cardiac Struct Metab. 1975;6:383-397.

34. Nef HM, Mollmann H, Elsasser A. Tako-tsubo cardiomyopathy (apical ballooning). Heart. 2007;93(10):13091315. 